\title{
Research on the Development and Utilization of Underground Space in Small and Medium-sized Cities in East China Based on Case Studies
}

\author{
Zhinan Gao ${ }^{1,2}$, Wanfeng Liu ${ }^{1,2}$, Xusheng $\mathrm{Li}^{1,2}$, and Yun Wei ${ }^{1 *}$ \\ ${ }^{1}$ School of Civil Engineering, Longdong University, Qingyang, Gansu province, 745000, China \\ ${ }^{2}$ Provincial Key Laboratory of Engineering Properties and Application of Loess, Longdong University, Qingyang, Gansu province, \\ 745000 , China
}

\begin{abstract}
The development and utilization of underground space is an effective way to solve the shortage of urban space capacity. It is also an inevitable choice for the sustainable development of urban underground space. The development and utilization of underground space in small and medium-sized cities in China started relatively late and lacked practical basis. This paper selects three representative small and medium-sized cities in east China to study the status quo, contents and achievements of underground space development and utilization, makes a comparative analysis, and puts forward the overall characteristics of underground space development and utilization in small and medium-sized cities, hoping to provide reference for the development and utilization of underground space in small and medium-sized cities in the future.
\end{abstract}

\section{Introduction}

By the beginning of 2017, China's urbanization rate had reached 57.35 percent, while the urbanization levels of Shanghai, Jiangsu, Zhejiang, Fujian and Shandong in eastern China were 87.6 percent, 67.7 percent, 67 percent, 63.60 percent and 59.02 percent, respectively, all higher than the Chinese average. With the acceleration of the pace of urban construction, the air and ground space tend to be saturated, which makes a series of "urban diseases" such as resource shortage, environmental quality decline and traffic congestion in east China become increasingly serious. The contradiction between man and land is increasingly prominent, and the development of cities is restricted. Rational development and utilization of underground space will be an effective measure to solve the problems of "human-land contradiction" and "urban disease" in the process of urban development.

As the main force to promote urban development in China, small and medium-sized cities play an increasingly prominent role in China's economic and social development and urbanization process. Rational development and utilization of its underground space is the basis of promoting sustainable urban development in China. Based on the research on the development and utilization of underground space in typical small and medium-sized cities in east China, it is of great significance not only to solve the problems in urban development, such as traffic congestion, insufficient parking space, and difficulties in infrastructure maintenance and transformation, but also to the development and utilization of underground space in small and medium-sized cities in China.

\section{Case analysis}

Kunshan city, Zhangjiagang city and Shaoxing city are representative cities of small and medium-sized cities in east China that have achieved some achievements in underground space development relatively early, so they are selected as cases. The basic situation of Kunshan City, Zhangjiagang City and Shaoxing City is shown in Table 1. 
Table 1. The basic situation of Kunshan City, Zhangjiagang City and Shaoxing City.

\begin{tabular}{ccccccc}
\hline Cities & Year & $\begin{array}{c}\text { Registered } \\
\text { Population (Unit: } \\
\text { 10 thousand } \\
\text { people) }\end{array}$ & $\begin{array}{c}\text { Gross Regional } \\
\text { Product (Unit: 100 } \\
\text { million yuan) }\end{array}$ & $\begin{array}{c}\text { Average Disposable } \\
\text { Income (Unit: 10 } \\
\text { thousand yuan) }\end{array}$ & $\begin{array}{c}\text { The Total } \\
\text { Area }\left(\mathrm{km}^{2}\right)\end{array}$ & $\begin{array}{c}\text { Population } \\
\text { Density } \\
\text { (people/km²) }\end{array}$ \\
\hline Kunshan & 83 & 3500 & 4.6 & 927.68 & 889 \\
Zhangjiagang & 2017 & 93 & 2500 & 4.9 & 999 & 1251 \\
Shaoxing & 80 & 1600 & 4.5 & 1202.54 & 526 \\
\hline
\end{tabular}

In the face of tight human-land relations and restricted urban development situation, based on economic conditions, Kunshan City (2009), Zhangjiagang City (2012), and Shaoxing City (2016) respectively conducted their underground space development and utilization planning.

\subsection{Main content of the development and utilization of Kunshan city's underground space}

Kunshan city underground space planning, as one of the special projects of Kunshan city general planning, has become an important basis for underground space planning and construction management.

2.1.1. Vertical layout. Based on the overground construction and transportation layout of Kunshan city, according to the engineering and hydrogeological conditions, the total demand and construction scale of underground space were predicted, and four vertical categories of underground space were determined, namely shallow layer $(0-10 \mathrm{~m})$, subshallow layer $(-10$ $30 \mathrm{~m})$, subdeep layer $(-30-50 \mathrm{~m})$ and deep layer (below $50 \mathrm{~m})[1]$.

\subsubsection{Special facilities.}

Putting forward the construction concept of underground space complex.

Underground walking system: make a reasonable plan for the underground floor of the main urban traffic arteries to form a perfect underground walking system and provide public activity space for pedestrians. Through a good connection between underground space and ground space, a direct pedestrian system of public buildings, underground commerce, bus stations and rail transit stations is established [2] to form an underground space complex.

Underground garage and underground carriageway: taking the construction of metro line 1 as an opportunity, the three-dimensional construction of main road intersections is carried out. Based on the construction of underground garages in surrounding plots, the construction of underground carriageway is carried out to alleviate the contradiction between people and vehicles on the ground of the city and provide guarantee for the development of the city.

Putting forward the development and utilization of the comprehensive pipelines.

In order to avoid the problem of repeated excavation of road surface for laying or maintaining pipelines, unified planning, unified design, unified construction and unified management are made for municipal pipelines, power pipelines, communication pipelines, gas pipelines, water supply and drainage pipelines and others, so as to form the development and utilization of underground comprehensive pipe corridor [3].

\subsection{Main contents of underground space development and utilization in Zhangjiagang city}

In order to facilitate the planning, management, control and guidance of underground space in the central city and key areas, Zhangjiagang city carried out underground space development and utilization under the guidance of detailed control planning.

\subsubsection{Urban underground space development and} utilization planning under the guidance of control rules. The central urban area is divided into four key control areas: the old urban area, the new urban area, the square green area and the transportation hub. On this basis, 13 underground space management units are divided to clarify the requirements of underground space layout structure, development function, development scale and development intensity of each management area [4] (Figure 1). According to the current situation of ground construction, underground development function and development demand, the development and utilization of underground space should be rationally planned and constructed. 


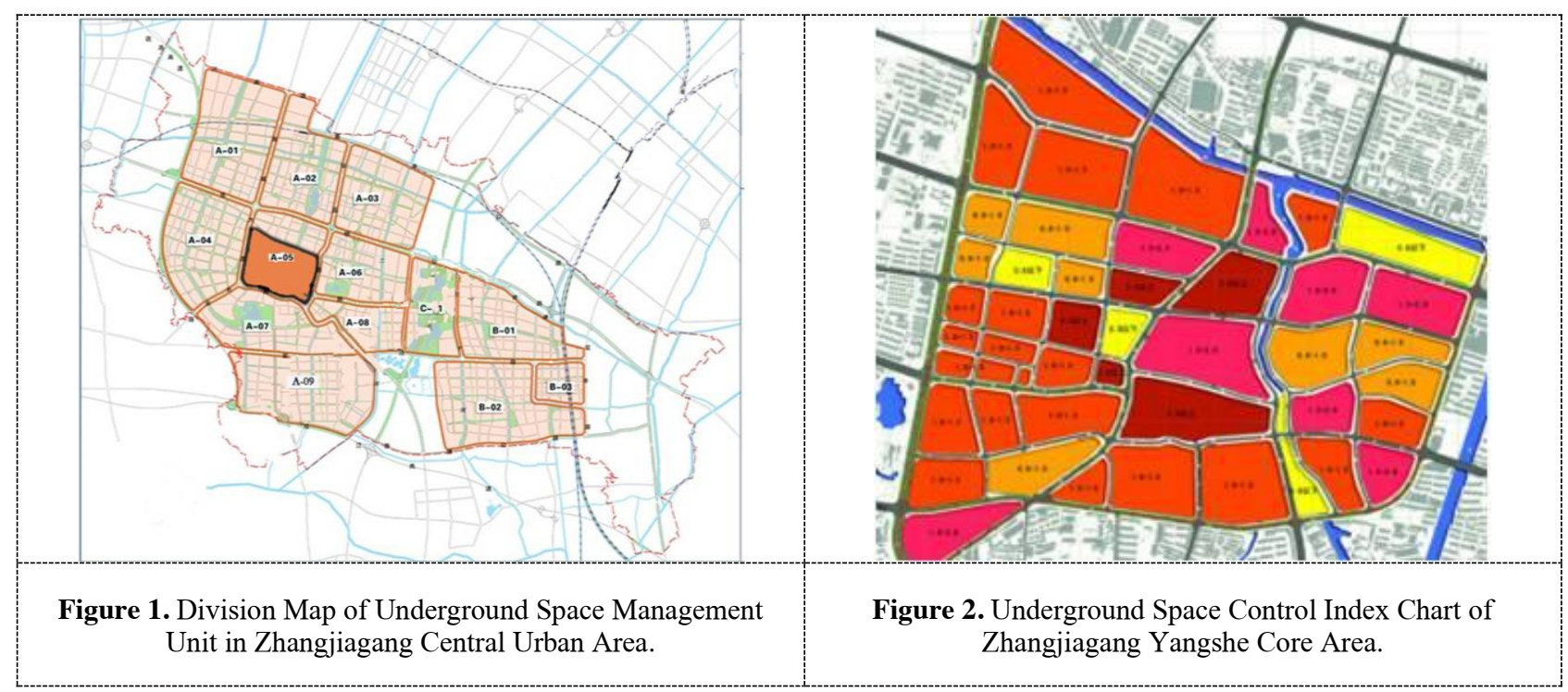

\subsubsection{Development and utilization of underground space in key areas.}

The control index of underground space of Yangshe Conmmercial Center is determined according to the division of key areas of underground space in the central city (Figure 2). As one of the core urban commercial areas, its underground space development is mainly commercial, supplemented by traffic, commerce, culture, leisure, parking, disaster prevention and other functions. The development scale is controlled at $0 \sim 100,000 \mathrm{~m} 2$, and the development depth is controlled at $-10 \mathrm{~m} \sim-30 \mathrm{~m}$. The ground floor is equipped with supporting facilities for commerce, entertainment, leisure and parking. The commercial area is $4.5 \mathrm{~m}$ high and the parking area is $3.5 \mathrm{~m}$ high. Subways, underground roads and underground parking lots are built on the second floor to solve traffic problems. The three underground floors are mainly for the construction of transit traffic roads [5].

Based on the underground space management unit in the central urban area, it is clear that the underground space development of Zhangjiagang hub station is centered on integrated traffic transfer, covering mixed functions such as road, rail transit, pedestrian system, parking, commercial facilities, comprehensive pipe corridor and civil defense [6]. The underground development scale is controlled in the range of 150 170 $\mathrm{m} 2$, the underground development of squares and green spaces adjacent to each hub station is controlled in the first and second floors underground, and the development of areas surrounding the rail facilities is controlled in the second and third floors underground.

\subsubsection{Multifunctional use of underground space.}

Multifunctional use of underground public parking: Since the construction of subway in Zhangjiagang, the underground parking lot no longer has the single function of parking. Light trucks can enter the warehouse through the underground parking lot to load and unload goods for commercial use; Pedestrians can enter the subway station directly from the underground parking lot [7].
Multifunctional use of underground complex: Based on the existing buildings on the ground and taking commerce as the leading function, the underground space in the central city is developed and utilized. Through the combined layout with the transportation hub, the underground cultural complex in the east of the city is formed, which has multiple functions such as transportation, leisure, entertainment, municipal administration, commerce and urban disaster prevention.

Multifunctional use of "combination of peacetime and wartime": The combination of underground transportation, underground storage and civil defense engineering facilities, as well as rational layout and systematic planning and construction, makes underground transportation an important transportation means for residents in peacetime and an emergency evacuation transportation line in wartime [8]. Underground storage facilities are used as convenient storage space for the above ground space in peacetime and for refuge in wartime and disaster.

\subsection{Main content of underground space utilization in Keqiao district, Shaoxing city}

Shaoxing city mainly adopts the way of combining the overall urban planning with the control detailed planning, and coordinating the underground space planning with the ground plan, to make the underground space development planning for the two core areas of the Kebei textile central business district and market district.

\subsubsection{Vertical planning of underground space.}

Based on the geological and hydrological conditions of Keqiao district, and in combination with the overall urban development trend determined by the general plan, it is determined that the vertical construction of underground space is concentrated in the middle and shallow layer within the range of $-20 \mathrm{~m}$.

Planning for different districts should be made according to the nature of land nature and development intensity. In the two central areas of the city, the development and utilization of underground space are 
mainly commercial, and the development depth is controlled at $-10 \sim-15 \mathrm{~m}$ (i.e., $2 \sim 3$ underground layers) [9]. The development and utilization of underground space of residential land is mainly for parking, and the development is controlled in $1 \sim 2$ floors underground (Figure 3).



\subsubsection{Layered layout planning of underground space}

According to the nature of urban land use and development intensity, corresponding functional suggestions for underground floors 1-3 are proposed [10] (see Table 2).

Table 2. Underground functions and aboveground functions correspond to the guidance control.

\begin{tabular}{|c|c|c|c|c|c|c|c|}
\hline $\begin{array}{l}\text { Underground } \\
\text { functions }\end{array}$ & $\begin{array}{c}\text { Underground } \\
\text { Parking }\end{array}$ & $\begin{array}{c}\text { Underground } \\
\text { Pipeline }\end{array}$ & $\begin{array}{c}\text { Underground } \\
\text { Facilities }\end{array}$ & $\begin{array}{c}\text { Underground } \\
\text { Storage }\end{array}$ & $\begin{array}{c}\text { Underground } \\
\text { Passage }\end{array}$ & $\begin{array}{c}\text { Metro } \\
\text { and Road } \\
\text { Tunnel } \\
\end{array}$ & $\begin{array}{c}\text { Underground } \\
\text { Municipal } \\
\text { Facilities } \\
\end{array}$ \\
\hline Residential & $\bullet$ & o & 0 & o & 0 & $x$ & $x$ \\
\hline $\begin{array}{c}\text { Road and } \\
\text { Transportation }\end{array}$ & ○ & $\bullet$ & $x$ & $x$ & $\bullet$ & $\bullet$ & 0 \\
\hline Square & $\circ$ & o & $x$ & $\bullet$ & $x$ & $x$ & o \\
\hline Industrial & $\circ$ & o & $x$ & $\bullet$ & o & $x$ & $x$ \\
\hline Commercial & $\bullet$ & o & $\bullet$ & ○ & $\bullet$ & ० & $x$ \\
\hline Public Services & • & ○ & $\bullet$ & $x$ & o & $x$ & $x$ \\
\hline $\begin{array}{l}\text { Municipal } \\
\text { Utilities }\end{array}$ & O & $x$ & $x$ & $\bullet$ & $x$ & $x$ & $\bullet$ \\
\hline Education & ○ & $x$ & ० & $x$ & $x$ & $x$ & $x$ \\
\hline Green Spaces & $\bullet$ & ० & o & $x$ & $\bullet$ & $\bullet$ & ० \\
\hline Waters & $\times$ & $\circ$ & $x$ & $x$ & $\times$ & $\circ$ & $\times$ \\
\hline
\end{tabular}

Note: $\bullet$ indicates suitable construction; $\circ$ indicates conditional construction; $\times$ indicates unsuitable construction.

\subsubsection{Planning of special facilities in underground space}

Underground transportation facilities: Based on the analysis of the radiation impact of subway stations, the connection points between underground tracks and conventional bus, car, bicycle and other transportation modes are systematically planned and laid out. Based on the analysis of pedestrian connectivity and distribution, the reasonable planning for three urban rail transit stations was planned. In the market block, the city plans 1 underground expressway and 6 underground pedestrian crossing channels, reasonably organizes traffic flow lines, and improves the integrity of the urban road network layout [11].
Underground municipal facilities: Focusing on the underground municipal pipelines, with the efficient low consumption as the goal, a circular underground common ditch was made combined with sections such as Keqiao passenger transportation center station and Chouduan road extension. It provides convenience for the rain and sewage recycling and realizes the underground substation and gas station.

\subsection{Analysis of development and utilization of underground space}

\subsubsection{Special planning level}


Table 3. Comparison of urban special planning contents.

\begin{tabular}{ccc}
\hline Cities & Municipal Facilities & Underground Transportation Facilities \\
\hline Kunshan & $\begin{array}{c}\text { To make unified planning for municipal } \\
\text { pipelines to form underground } \\
\text { comprehensive pipeline corridors. }\end{array}$ & $\begin{array}{c}\text { To build an underground space complex } \\
\text { based on the construction of underground } \\
\text { pedestrian streets, underground parking lots, } \\
\text { and underground driveways. }\end{array}$ \\
Shaoxing & $\begin{array}{c}\text { To build 1 underground freeway, } 6 \\
\text { ring-shaped underground common trench. }\end{array}$ & $\begin{array}{c}\text { underground pedestrian crossings, and } \\
\text { rationalize traffic flow. }\end{array}$ \\
\hline
\end{tabular}

Special planning of underground space in Kunshan city: The underground complex is formed by the planning and construction of underground pedestrian system, underground garage, underground sidewalk, underground public service facilities and underground municipal pipelines, laying the foundation for efficient utilization of urban underground space.

Underground space of Shaoxing city under special planning: based on the current situation of urban roads, squares and green space construction in ground planning, develop underground space to make up for the missing functions on the ground. According to the demand of underground space in residential area, industrial area, square, large green space and other functional areas, the underground parking, underground storage and other facilities are planned and arranged in a comprehensive way to form the mutual coordination of underground space, contacting with the above ground functional areas and realizing the compound development mode.

Therefore, on the basis of general regulations, the planning and construction of various facilities and systems of urban underground space will become a trend in the development and utilization of underground space in small and medium-sized cities in China, which will make the utilization of underground space in small and medium-sized cities more multi-functional and systematic.

\subsubsection{Regulatory plan level}

Table 4. Planning contents of urban underground space under the guidance of regulatory plan.

\begin{tabular}{cccc}
\hline Cities & Development Depth & Development Layers & Development Functions \\
\hline $\begin{array}{c}\text { Zhangjiagang Yangshe } \\
\text { Core Area }\end{array}$ & $0 \sim-30 \mathrm{~m}$ & Basement 1 to Basement 3 & $\begin{array}{c}\text { Mainly to commerce, functions } \\
\text { like transportation, culture, } \\
\text { leisure, parking, disaster }\end{array}$ \\
$\begin{array}{c}\text { Shaoxing Kebei Textile } \\
\text { Central Business District }\end{array}$ & $-10 \sim-15 \mathrm{~m}$ & Basement 2 to Basement 3 & $\begin{array}{c}\text { prevention, and other functions } \\
\text { are integrated into one. }\end{array}$ \\
\hline
\end{tabular}

Zhangjiagang city's underground space under the regulatory plan: The key area of underground space development scale, development depth and development capabilities, key areas surrounding the development and utilization of underground space for control guidance, the city's center and transportation hub of two underground complex [13] were built, providing guarantee for the coordinate development of underground space.

Shaoxing city's underground space under the regulatory plan: The overall layout of urban overground and underground space is made, and the main functions of vertical planning depth and layered planning is determined, which laid the foundation for the rational development and utilization of underground space in the central city.

It can be seen that in the development of small and medium-sized cities in China, regulatory plans no longer merely guide urban surface planning and construction, but take urban underground space development and utilization planning as the key content.

\section{Development and utilization characteristics of underground space in small and medium-sized cities}

Through the content and analysis of underground space development and utilization in Kunshan, Zhangjiagang and Shaoxing, this paper summarizes the following characteristics of underground space development and utilization in small and medium-sized cities in east China.

\subsection{Scientific development system}

First, the planning system of underground space development and utilization is constantly improving. In the general planning stage, the detailed planning stage and the special planning stage, the small and mediumsized cities respectively put forward requirements for the development and construction of underground space from the macro, medium and micro perspectives [14].

Second, the method of forecasting underground space demand is reasonable, that is, according to the analysis of the ground construction volume in different functional areas of the city, the regional land value combined with 
the demand for the underground construction intensity of different land uses. Take residential land and land for public facilities (including the land for commercial service, public management, and public service) as examples:

$$
Q_{R i}=\frac{N}{n} * \alpha * \beta * \varphi * \gamma
$$

Among them, $R_{i}$ is the $i$-th residential area, $N$ is the planned population, $\mathrm{n}$ is the average number of households, $\alpha$ is the average car ownership per household, $\beta$ is the building area occupied by each car, $\varphi$ is the underground parking rate, and $\gamma$ the percent update for the old city.

$$
\begin{aligned}
& Q_{A i}=S^{*} F A R^{*} L \\
& Q_{B i}=S^{*} F A R^{*} L
\end{aligned}
$$

Among them, $A_{i}$ is the $\mathrm{i}$-th public management and public service zone, $B_{i}$ is the $i$-th commercial servcie area, $\mathrm{S}$ is the construction land scale, FAR is ground floor area ratio, and $\mathrm{L}$ is scale ratio of underground buildings to above-ground buildings.

$$
\begin{aligned}
& Q_{A T_{i}}=S * F A R * \lambda * \varphi \\
& Q_{B T_{i}}=S * F A R * \lambda * \varphi
\end{aligned}
$$

Among them, $\mathrm{AT}_{\mathrm{i}}$ is the $\mathrm{i}$-th underground allocated parking lot in public management and public service area, $\mathrm{BT}_{\mathrm{i}}$ is underground allocated parking lot in commercial service area, $\mathrm{S}$ is the construction land scale, FAR is ground floor area ratio, $\lambda$ is the provision of parking area for $100 \mathrm{~m}^{2}, \varphi$ is underground parking rate.

Lands with fixed underground space needs (civil defense facilities, subways, etc.) are forecasted rigidly, while those with uncertain underground space needs (business services, etc.) are forecasted elastically.

After determining the amount of underground space construction in each area/region, the total amount of urban underground space construction is summarized. The demand for underground space can be expressed as a function:

$$
Q=\sum_{i=1}^{\mathrm{n}} f_{1}\left(x_{1}, x_{2}, x_{3} \ldots x_{n}\right)
$$

Among them, $\mathrm{n}$ is the total area/plot in the analysis area, $x_{i}$ is the amount of underground space required for $i$ area/plot.

Third, the "consensus" on the sustainable development and utilization of underground space in small and medium-sized cities is formed. Kunshan, Zhangjiagang and Shaoxing all adhere to the principle of "planning first, construction later", and determine the development scale and depth of underground space through comprehensive consideration of urban overground construction, traffic layout, engineering geology, hydrogeology and total demand for underground space. The development and utilization of underground space in the core area shall be under key control to form a coordinated development mode above ground and underground.

\subsection{Multifunctional utilization mode}

The functions of underground space development and utilization in small and medium-sized cities are mainly embodied in five aspects: disaster prevention, easing traffic congestion, pipeline laying, development of commerce and storage security. The planning and construction among the functions are no longer simple, but are gradually developing in combination.

First, in the central business district and transportation hub area of small and medium-sized cities, an underground complex with multiple functions of commerce, transportation, leisure and entertainment is formed to realize the efficient use of underground space.

Second, the planning of underground space in small and medium-sized cities is being combined with the construction of civil defense projects to realize the multifunctional use of civil defense in peacetime and wartime.

\subsection{Systematization of development levels}

The vertical planning depth of underground space in small and medium-sized cities is not only staying at the first underground floor, but also moving towards the second and third underground floors.

First, the development depth of underground space in small and medium-sized cities is mostly concentrated in the middle and shallow layer of $-20 \mathrm{~m}$. The commercial and service land in the central city is generally developed to three underground floors with a depth of $-10 \sim-15 \mathrm{~m}$.

Second, the first underground floor of small and medium-sized cities is mainly commercial, supplemented by entertainment and parking. The second underground floor is mainly for parking, supplemented by civil defense and underground roads. The third underground floors mainly function as underground rail transit.

\subsection{Standardization of regulatory plan regulation}

Faced with the problem of low land intensification, in order to give better play to the potential of land, the governments put forward relevant indexes for the underground space in central and important areas of small and medium-sized cities to adapt to the development trend of expanding the scale of underground space development and utilization under the guidance of detailed control planning.

The planning in the regulatory plan stage is to improve the utilization rate of land and realize the overall development of the overground and underground combined with the ground functions to control the development scale, depth and intensity of underground space on the basis of the geological conditions.

\section{Conclusion}

With the acceleration of urbanization in China, the rational development and utilization of underground space in small and medium-sized cities has gradually become an irreversible trend of urban space development. 
Through case analysis, this paper summarizes the overall characteristics of underground space development and utilization in small and medium-sized cities in east China, including scientific underground space development system, multi-functional development mode, and systematic development hierarchy, standardization of control rules and control, and precision of development technology. It is expected that the application of GIS technology will provide a basis for the rational development and utilization of underground space in small and medium-sized cities, and provide a guarantee for easing traffic congestion, saving resources, strengthening land intensification and improving living environment.

\section{Acknowledgments}

This work was supported by the Second batch of the industry-academia collaborative education project of the Ministry of Education in 2018(201802142005), "Thirteenth Five-Year Plan" education science plan in Gansu Province (GS [2018] GHBBK030), and 2018 Education and Teaching Research Project in Longdong University (2018-16), Social and Science Planning Project in Gansu Province (YB134).

\section{References}

1. Zhai S.(2015) Practice of Special Planning for Underground Space in Urban Master PlanningTaking Kunshan City as an example.Urbanism and Architecture, 2:42.

2. Cheng B.(2012) Construction of Underground Urban Complex with Metro tunnel. Chinese Journal of Underground Space and Engineering, 8:13441347.

3. Xu X.Q.(2010) Planning and Administration of Urban Renewal Area and Utilization of Underground Space:A Case Study of Shenzhen Huaqiangbei District. Urban planning forum, 7:3035 .

4. Liu Y.(2016) Research on Underground Space Planning of Third-tier/fourth-tier Cities. Chinese Journal of Underground Space and Engineering, 3:593-599.

5. Liu W.D., Pan N.N.(2012)Exploitation and Utilization of Underground Space in Urban Core Areas from the Perspective of Regulatory PlanningA Case Study of Ouhai City Center District, Wenzhou. In: Diversity and Inclusion-2012 China Urban Planning Annual Meeting. Kunming.

6. Li J.X., Wei W.S.(2012) Discussion of Comprehensive Utilization Plan of Urban Key Area Underground Space_C Case Study of Guangzhou Grand City Plaza Area. Chinese Journal of Underground Space and Engineering, 3:461-466.

7. Wu Y.H.(2009) Function Mixture-Complex Advance of Underground Space in Modern City.
Chinese Journal of Underground Space and Engineering, 2:211-214.

8. Huang S.B.(2016) Civil Air Defense Engineering Construction and Development and Utilization of Urban Underground Space. Construction Materials \& Decoration, 11:69-70.

9. Qin Y.C., Zhang E.Y., Liu D.F.(2003) On the System Assessment of Sustainable Urban Development-Kaifeng City for Example. System Engineering Theory and Practice, 6:1-8+35.

10. Xiao Q.Y., Cai G.Y.(2014)Underground Space Utilization Of Small And Intermediate Cities: Shaoxing Case. City Planning Review, 1:42-47.

11. Chen Z.L., LIU H.(2011) Master Plan of Urban Underground Space. Southeast University Press, Nanjing.

12. Cai G.Y.(2014) Research on Planning System Of Urban Underground Space-Taking Zhejiang Province as an example. XI'AN University of Architecture and Technology, Xi'an.

13. Zhang A., Yan G., Xie R.X. etc.(2009)Development control over underground space in the regulatory detailed planning system. City Planning Review, 2:20-24.

14. Shu Y., Liu K., Zhang M.L. etc.(2007) Theoretical Study and Practice of Underground Space Planning. Planners, 10:5-8. 